\title{
INTERACTIONS AMONG LEARNING STYLES, LANGUAGE LEARNING STRATEGIES AND GENDER OF EFL LEARNERS
}

Rizka Nurul Atikal

${ }^{1}$ Corresponding author, English Education Department, Sekolah Pascasarjana, Universitas Pendidikan Indonesia, Indonesia; rna10@upi.edu

\begin{abstract}
Many studies have investigated isolated dimensions of learning styles (e.g. field independence/dependence) for their role in foreign language learning, but relatively few studies have used a comprehensive learning styles instrument to determine predictors of language learning strategies used by students. Hence, employing the descriptive and correlational method, this study aimed to identify students' minor, major, and negligible learning styles, students' usage of language learning strategies, the difference in the learning styles and language learning strategies based on gender, and the relationships among those three variables. A total of 30 students enrolling in the first year of senior high school were given two kinds of questionnaire, the Indonesian version of PLSQ and SILL. The result revealed gender differences only occurs in compensation strategy, in favor of female students. Furthermore, the correlational study revealed significant relationships between visual style and cognitive and metacognitive strategies; between auditory style and cognitive and compensation strategies. Moreover, social strategies are correlated with tactile, group, and individual styles. These findings are useful for both teacher and student to employ strategies suitable with their learning styles.
\end{abstract}

Keywords: learning styles, language learning strategies, gender

\section{Introduction}

Over the last three decades, there is a growing appreciation for the contribution of such variables as learning style and learning strategy to language learning success in recent ESL/EFL classroom research (Ehrman and Oxford 1990; Ehrman and Oxford 1995; Wharton, 2000; Tabanlioglu, 2003; Oxford, 1995; Littlemore, 2001). The interest towards these topics increased from the endeavor in finding teaching methods, classroom practices, and instructional materials that will enhance better language instruction. However, regardless of each one of these endeavors, there has been a growing issue that students have not advanced as much as expected. Since there are extensive individual differences in learning a language, what works for one student might not work for another. Therefore, some researchers in the field moved their center of studies from language teaching methodology to 
language learners and the factors influencing their language learning. This alter of the point of convergence has prompted a growth in the quantity of studies done with respect to student characteristics in second or foreign language learning.

Learning Style and Language Learning Strategies (LLS) are two of the most major viewpoints researchers have focused on. Learning styles embody unconscious individual learner traits while learning strategies are particular behaviors employed by the learner to make learning more effective. Whereas learning styles are internally based traits, often not perceived or consciously used by learners, learning strategies are external skills used consciously by students to facilitate their learning. Compared with learning strategies, learning styles are relatively stable characteristics which learners convey to the learning situations.

One of the well-known determining factors of students' differences in learning styles and language learning strategy is gender. Some studies revealed girls are superior to boys in language learning (e.g., Arnot et al., 1996; Boyle, 1987; Burstall, 1975), while some others found the opposite results (e.g., Biigel \& Buunk, 1996; Morris, 1998; Scarcella \& Zimmerman, 1998). Some studies suggest the difference is due to the preferred learning styles by male and female learners. For example, Oxford (1994) suggests that a 'female learning style' may be relatively but characteristically global (rather than analytical), field dependent (rather than field-independent), reflective (rather than impulsive) and auditory (rather than visual). In strategy, male students tend to use more communicative strategies than their female counterparts.

Distinct as they are, these two concepts nevertheless bear a close relationship to each other. Both contain cognitive and affective factors and are predictors of language proficiency. Brown (1994) further pointed out that learning strategies do not operate by themselves, but rather are directly linked to the learner's innate learning styles and other personality-related factors. It is proposed that learning style encompasses learners' general inclination to use certain learning strategies while avoiding others (Oxford, 1990).

Various researches also suggested that learning styles may altogether influence learners' learning strategy choices regardless the different research instruments and settings (e.g. Carson and Longhini 2002; Ehrman and Oxford 1990; Littlemore 2001; Rossi-Le, 1995). For instance, Rossi-Le (1995) administered a study in which she focused on the perceptual learning styles of adult immigrant learners and she investigated the relationship between favored learning styles and strategy preference in an ESL context. The outcomes also show important relationships between learning styles and strategies. Interactive strategies were used by learners who favored group learning. The students who preferred the kinesthetic and tactile group preferred authentic language use. The learners who preferred the visual styles chose visualizations a strategy. Finally, though limited in number, the individual learners preferred model building.

The relationship between learning styles and strategies determines that the research of linking strategies to styles will bring more fruitful results to both fields and would be beneficial to both learning and teaching. However, although researchers have examined the role of learning styles in foreign language learning, many studies have investigated isolated dimensions of this construct (e.g. field independence/dependence). Relatively few studies have used a comprehensive learning styles instrument to determine predictors of foreign language learning strategies used by students. Thus, the objectives of this research is to 
analyze the dimensions of learning styles (visual, auditory, kinesthetic, tactile, group, and individual) and its relation to the strategies used by students in language learning, as well as to investigate students learning style preferences and their language learning strategies based on their gender.

Learning styles, language learning strategies, and gender are correlated with one another in a way that the language learning strategies employed by learners are influenced by their learning styles and gender. Students have different preferences in learning styles and language learning strategies, and one of differential factor is gender. Studying the relationship between learning styles, language learning strategies, as well as seeing them from gender perspective will bring more fruitful result in understanding language acquisition in a more 'human' way because it takes individual differences into account.

Therefore, this study was aimed to answer the following questions:

1. What are the major, minor, and negligible perceptual learning style of the students?

2. What kind of language learning strategy are used by the students?

3. Is there any difference in the learning style and language learning strategies of male and female students?

4. Is there a relationship between students' learning style and their language learning strategy preferences?

Since most of the previous research in this field were conducted towards adult language learners, this study focused on investigating the school-aged students. Hence, this study might prove useful to both language teachers and learners in schools. Teachers' awareness of the students' innate learning styles may affect their language learning strategy, so it will give better insight for teachers to organize and employ instructional materials accordingly. As for the students, an increase of their awareness of this matter might make them not only more prepared for learning, but also more analytic about their learning styles and the strategies they make use of.

Practically, by knowing students' major, minor, and negligible learning styles, students and teacher can work together in maximizing the learning environment to match students' preferences. Moreover, understanding the learning preferences of male and female students will give a fruitful insight on how teachers should treat both parties. Finally, understanding the relationship between learning styles and language learning strategy will encourage both parties to employ appropriate teaching and learning strategies to match their preferences so that the language learning activities can be more effective and enjoyable.

\subsection{Learning Styles}

According to Brown (2007), "styles are those general characteristics of intellectual functioning (and personality type, as well) that pertain to you as individual, and that differentiate you from someone else." Dunn and Dunn (1979, as cited in Reid, 1987) also define learning styles as "a term that describes the variations among learners in using one or more senses to understand, organize, and retain experience" (p. 89). Hence, styles will characterize a general or dominant pattern in your thinking or feeling. So styles vary across individuals. The way we learn and approach things in general is a result of the vague link between personality and cognitive; this style is referred by Cognitive Style. In educational context, it is usually referred as Learning Styles. 
Learning styles mediate between emotion and cognition (Behabadi, 2013, p. 43) . For example, a reflective style is from a reflective personality and reflective mood. And impulsive style, on the other hand, usually arises out of an impulsive emotional state. People's styles are determined by how they internalize their total environment, and since that internalization process is not strictly cognitive, physical, affective, and cognitive domains merge in learning styles. Some would claim that styles are stable traits in adults. However, even though an individual would appear to have a tendency towards a certain preference, different 'context will evoke different styles within the same individual. Perhaps, according to Brown, "successful person and intelligent person is one who is bicognitive - one who can manipulate both ends of a style continuum."

The perspective towards learning styles vary in terms of scope and depth. In this respect, scholars have divided learning styles in various ways. For instance, Keefe (1979) includes the three dimensions of behavior: cognitive, affective, and behavior. Meanwhile, Ehrman \& Leaver (2003) divided the bipolarized styles as follows: field independence vs. field dependence; random (non-linear) vs. sequential (linear); global vs. particular; inductive vs deductive; synthetic vs. analytic; analogue vs. digital; concrete vs. abstract; leveling vs. sharpening; impulsive vs. Reflective.

Another widely used dichotomy is the Perceptual Learning Style (PLS) proposed by Reid (1987) which includes the following styles:

1. Visual: learns more effectively through seeing

2. Auditory: learns more effectively through hearing

3. Tactile: learns more effectively through touch (hands-on)

4. Kinesthetic: learns more effectively through complete body experience

5. Group: learns more effectively through working with others

6. Individual: learns more effectively through working alone

As an intriguing area for language learning research, an expansive number of empirical investigations endeavored to call attention to the importance of learning styles in second and foreign language learning. Researchers attempts or endeavors to give better insights of successful language learning and learners have identified different learning styles reported by learners or observed by researchers in various learning settings. They have explored learning styles as far as their examples or classes and sub-classes, learners' most preferred or frequently utilized patterns in learning a language, and so forth. Such endeavors appear to be significant since they have contributed enormously to our comprehension of learning.

Bailey, Onwuegbuzie, and Daley (2000) conducted a research aimed to predict foreign language achievement using learning style at college level. The investigation meant to indicate what sort of learning style will result in high and low accomplishment. the study included 100 college students enrolling in either French or Spanish class. Findings propose that higher achievers in this sample will in general like casual classroom structures and to lean toward not to get information by means of the kinesthetic mode, and that information of whether a learner is responsible in finishing tasks and whether he or she requires mobility in learning settings expands the predictive power of classroom design and kinesthetic preference.

A study by Behabadi and Behfouz (2013) likewise attempted to explore the traits of good language learners identified with learning styles. The subject of the examination is 34 Iranian IELTS examinees who got over 6 band score. They were given the learning style and style 
recognition questionnaire, interviewed about their learning style, and they were givensome information about their learning styles and self-recognition. The research uncovered that there is a high relationship in IELTS test and having kinesthetic, auditory, and visual styles, yet not with tactile style. The investigation also revealed that high achiever in IELTS like to work independently to in group.

\subsection{Language Learning Strategy}

One of the earliest researchers in Language Learning Strategies (LLS), Rubin (1975, p.43; 1981, pp.124-126) provided a very broad definition of learning strategies as "the techniques or devices which a learner may use to acquire knowledge", those which contribute directly to learning, and those which contribute indirectly to learning. Tarone (1983) defined a learning strategy as "an attempt to develop linguistic and sociolinguistic competence in the target language - to incorporate these into one's interlanguage competenc." Later Rubin (1987) stated that learning strategies "are strategies which contribute to the development of the language system which the learner constructs and affect learning directly."

Oxford (1990) classified LLS into six groups: memory strategies (which relate to how students remember language), cognitive strategies (which relate to how students think about their learning), compensation strategies (which enable students to make up for limited knowledge), metacognitive strategies (relating to how students manage their own learning), affective strategies (relating to students' feelings) and social strategies (which involve learning by interaction with others).

There have been a number of studies involving LLS in its relation with successful and unsuccessful language learners. For instance, Phillips (1991) used SILL and TOEFL scores to investigate the relationship between adult ESL students' language learning strategies and proficiency. Phillips reported strong relationships between ESL/EFL SILL frequencies and English proficiency levels. Oxford, Park-Oh, Ito and Sumrall (1993a, b), studying 107 high school students of Japanese, also reported a significant relationship between strategy use and language achievement scores. Park (1994) also used SILL to investigate the relationship between strategy use and proficiency in Korea. In this study, standardized test scoresTOEFL scores-were used to measure proficiency. Park indicated a linear relationship between strategy use and language proficiency.

\subsection{Relationship Between PLS and LLS}

Carson and Longhini (2002) investigated the relationship between language learning styles and strategies of the diarist/researcher in a naturalistic setting. The study utilized Oxford's SILL and the Style Analysis Survey (SAS) to compare categories that emerge in the diary entries. The analysis indicated that the diarist's learning strategies were often affected by her learning styles. For example, the diarist, with a global learning style, always suspended bits of partly understood language until they formed a large pattern. The diarist was also aware of the difficulty of utilizing strategies not preferred by her styles. For example, the diarist was introverted and often felt uneasy when communicating with people she did not know well.

A study by Tabanlioglu (2003) investigated the relationship in a formal education context. A total of 60 students of English for Academic Purposes (EAP) were asked to 
complete two questionnaires. One was used to identify students' perceptual learning style preferences and the other was used to identify students' learning strategies. The results revealed that visual styles had a significant relation with affective strategies; auditory styles had significant relationships with memory, cognitive, affective, and social strategies; there was a significant relationship between the individual learning style and compensation strategies; none of the learning styles had a significant relationship with metacognitive strategies. In conclusion, the study suggests that students' learning styles may affect their choice of strategy.

\subsection{Gender in Language Learning}

Extensive empirical research has been conducted in the field of education and gender since the mid-1960s. The most well-known gendered aspect of second and foreign language learning, and indeed the key issues for many, is probably that girls tend to perform better than boys (e.g., Arnot et al., 1996; Boyle, 1987; Burstall, 1975). In some countries girls do so much better that entrance requirements are lowered for boys applying to attend Englishmedium schools (Sunderland, 2000, p. 204).

Examination results however always need treating with caution, and examination validity needs to be questioned. Any apparent superior proficiency as regards scores may always be (partially) a function of the test (Sunderland, 2000, p.204). As regards performance in class, including class tests, and on homework, teachers may believe that girls are the better language learners due to teachers' expectations and treatment of students; girls may for example be treated in subtle ways more encouragingly than boys. Clark (1998) suggests that because girls tend to present neater work, teachers may respond to girls disproportionately positively.

Girls' often superior foreign language performance and achievement in languages might be related to more general learning patterns or styles. Oxford (1994) suggests that a 'female learning style' may be relatively but characteristically 'global' (rather than analytical), 'field dependent' (rather than field-independent), reflective (rather than impulsive) and auditory (rather than visual).

As gender is an issue with important theoretical and pedagogical implications in second language learning, it has received some attention in language learning strategy research (e.g., Oxford, 1993; Oxford, Young, Ito \& Sumrall, 1993; Oxford, 1995; Young \& Oxford 1997). These studies have found that gender can have a significant impact on how students learn a language. few gender differences (or, more accurately, gendered tendencies) have been found alongside the similarities (Bacon \& Finnemann, 1992; Goh \& Foong, 1997; Nyikos, 1990; Oxford, 1994; Iran, 1988; Willing, 1988), mainly concerning frequencies of use. For example, Goh and Foong found that female Chinese students of ESL in Singapore tended to use 'compensation' (e.g., guessing unknown words) and 'affective' (e.g., anxiety management) strategies significantly more than their male counterparts.

An emerging theory for this gender difference proposes that although sometimes males surpassed females in the use of a particular strategy, females employ more learning strategies or employ strategies more effectively (Erhman and Oxford, 1989; Nyikos, 1990; Oxford, 1994; Sheorey, 1999). Oxford and Nyikos (1989) who looked at the strategies used by 1200 
university students, concluded that gender differences had a "profound influence" (p.296) on strategy use, and that females used strategies more frequently than males.

Ehrman and Oxford (1989) discovered significant gender differences in the SILL (favoring women) in the following strategy classifications: general study strategies, strategies for authentic language use, strategies for searching for and communicating meaning, and metacognitive or self-management strategies. Moreoever, Sy (1994) discovered that students of English in the Republic of China showed significant gender differences on the SILL. In that study, females significantly surpassed males in their use of cognitive, compensation, metacognitive, and social strategies.

Individual differences should be taken into account in language learning as they may affect the learning outcome through the kind of input received by students. their differences, including their learning styles and gender, may influence their utilization of learning strategies. Distinct as the two concepts of language learning styles and strategies are, they found to be interrelated concepts as suggested by a number of researchers in the field. The relationship between learning styles and strategies determines that the research of linking strategies to styles will bring more fruitful results to both fields and would be beneficial to both learning and teaching. At a practical level, once learners get to know their style preferences, it may be easier for them to see why they prefer using certain learning strategies and not others. And this awareness would help learners develop the flexibilities to cope with different learning contexts and ultimately achieve learner autonomy.

\section{Method}

This is a descriptive and correlational study based on a survey research conducted for the purpose of making descriptive assertions about some population. This study aims at finding out the major, minor, and negligible perceptual modalities, the learning strategies, and to investigate the relationship between the learning style and language learning strategies. Moreover, to get more insights on the variables, a control variable of gender was added to see whether there is any difference between female and male students' learning styles and language learning strategies.

\subsection{Respondents}

The participants of this study were 30 students of one of Senior High School in Bandung, Indonesia, where English is taught as a compulsory subject. The subjects consisted of 15 male and 15 female students (50:50) in favor of the gender difference study. The sample were selected randomly from the first grade students.

\subsection{Instruments}

\subsubsection{Perceptual Learning Style Preference Questionnaire (PLSPQ)}

Perceptual Learning Style Preference Questionnaire (PLSPQ) created by Reid (1987) is a self-revealing survey created based on previously existing learning style instruments with a few changes proposed by non-native speaker sources and US specialists in the field of linguistics. The survey, which was structured and approved for non-native speakers, comprises of five groups of statements on every one of the six learning style preferences to be estimated: visual, auditory, kinesthetic, tactile, group learning, and individual learning. 
The first four classes comprise the perceptual learning style classifications and the other two make up the social classification. The respondents reacted to 30 questions based on a five point Likert scale, going from emphatically consents to firmly oppose this idea. An Indonesian adaptation of PLSPQ was utilized in this study to ensure its understandability.

\subsubsection{Strategy Inventory for Language Learning}

The second instrument utilized in this examination is the Strategy Inventory for Language Learning created by Oxford (1990). It is a self-report, paper and pencil study . The SILL was initially intended to survey the recurrence of utilization of language learning strategies by students at the Defense Language Institute in California. The second instrument utilized in this research is the Strategy Inventory for Language Learning created by Oxford (1990). It is a self-report, paper and pencil questionnaire. The SILL was initially intended to survey the recurrence of utilization of language learning strategies by students at the Defense Language Institute in California. The SILL (Version 7.0) comprises of six subsections and each area speaks to one of the six classes of LLS, which the students did not know at the moment of taking the survey. The 50 statements follow the general arrangement 'I do such and such' and learners react on 5 point Likert scale going from 1 'Never or almost never true of me' to 5 'Always or almost always true of me .' The participants were required to write down the appropriate responses on a different answer sheet. The values assigned to each item in each section are added and then divided into the number of items in each section.

\subsubsection{Gender}

To investigate gendered tendencies in this study, both questionnaires (PLSPQ and SILL) required the subjects to fill in their name and gender for identification. This data divides the subjects into two groups, male and female, to be compared.

\subsection{Procedures}

This study was conducted on November $2^{\text {nd }}, 2018$. Both of the questionnaires were completed during class. First, the students were asked to fill in their name and gender in both questionnaires for identification. Then, the researcher explained briefly how to fill in the questionnaires. To increase the credibility of the responses the researcher reminded the students that they should be sincere in their answers and they shouldn't spend too much time on any of the items. The students were also asked to give an immediate response and that they shouldn't hesitate and change their answers. Students first filled in the Indonesian version of the Perceptual Learning Style Preference Questionnaire. Then, they were asked to complete the Indonesian version of Strategy Inventory of Language Learning. The questionnaires were collected and the responses were entered into the computer for data analyses by using Microsoft Excel and Statistical Package for The Social Sciences (SPSS) version 16.0.

Regarding the analysis of the results obtained from the Perceptual Learning Style Preference Questionnaire (PLSPQ), descriptive statistics was used. The scores of students' answers on the Likert's scale were calculated and multiplied by two in order to group the students according to their major, minor, and negligible learning style preference categories. Major is the style in which students favor the most; minor means students are okay to learn 
with such style; negligible is the style that students find difficulties to work with. Below are the criteria (Reid, 1987).

Table 1. Classification of Major, Minor, and Negligible Learning Style

\begin{tabular}{ll}
\hline Score & Classification \\
\hline $\mathbf{3 8}-\mathbf{5 0}$ & Major Learning Style \\
& Preference \\
\hline $\mathbf{2 5}-\mathbf{3 7}$ & Minor Learning Style \\
& Preference \\
\hline $\mathbf{0 - 2 4}$ & Negligible Learning Style \\
& Preference \\
\hline
\end{tabular}

A t-test was conducted to identify whether there was significant difference in the learning style preference between males and females. Similar statistical procedures were used to analyze the data obtained from the Strategy Inventory for Language Learning (SILL) to find out the usage rate of the strategies.

Finally, in order to reveal whether there was a significant relationship between the learning styles and the language learning strategies the Pearson correlation was used. This test was suitable since the data are distributed normally according to Saphiro Wilk's test conducted earlier towards the raw data. The statistical analyses were conducted by using the Statistical Package for Social Sciences (SPSS).

\section{Finding and Discussion}

\subsection{What are the major, minor, and negligible perceptual learning style of the students?}

Using descriptive statistical analysis, the students were divided according to their major, minor and negligible learning styles. The raw scores on the survey of perceptual learning style (see Figure 1) indicated that group learning was the most preferred major learning style (17 out of 30) of all participants, closely followed by Auditory style (14 out of 30). Visual style was their preferred minor learning style (23 out of 30), followed by Individual learning (18 out of 30). The participants showed negligible preferences for tactile, group, and individual learning. These learning style preference categories are not mutually exclusive; a learner may have more than one learning style preference.

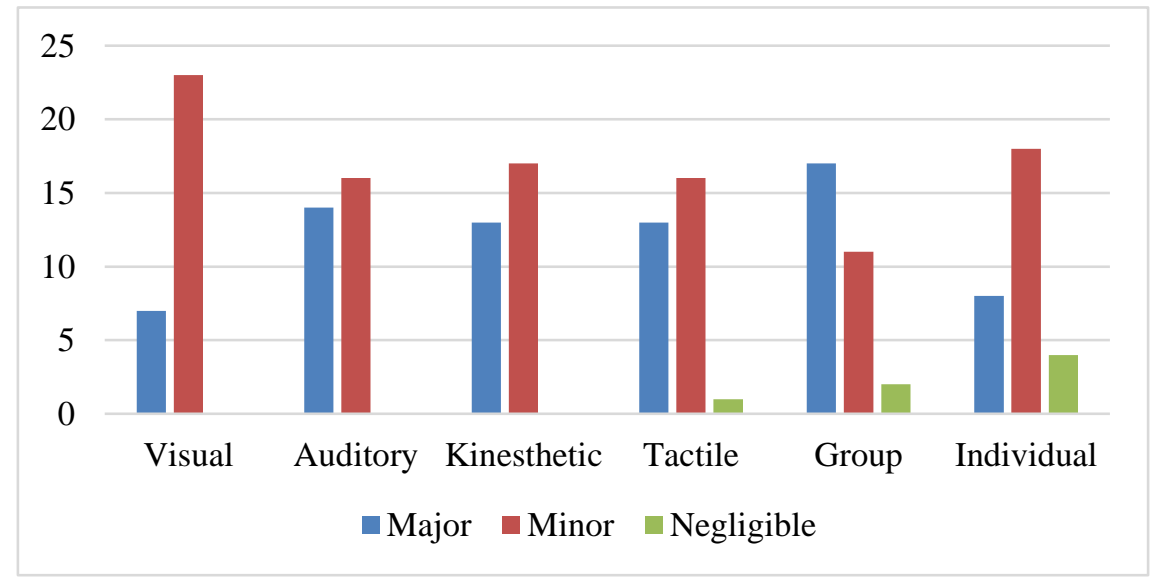

Figure 1. Major, Minor, and Negligible Learning Styles 
There is a remarkable result regarding Group vs. Individual Learning style. There were 17 students who has group learning as their major learning style, and 18 students claimed they do not mind working individually (minor style). It means that even though there is a very small number of students who are negligible in these styles, majority of the students work well in both situations. This contradicts to some studies stating language learners prefer individual to group learning (Behabadi, 2013, pp. 41-49; Tabanlioğlu, 2003; Wintergerst, 2001; Reid, 1987). This result confirmed the teacher's statement during the preliminary interview. She said that students are more interested in group work rather than individual tasks. This might be a result of the current Indonesian curriculum that contains a huge amount of group work within students.

Moreover, the outstanding number of students possessing visual style as their minor learning style suggest how students process information surrounding them. As we know, in this digital era, students acquire more language from the internet - reading, seeing pictures and watching videos. Therefore, a lot of students have developed visual learning style even though only a few of them have it as major style.

\subsection{What kind of language learning strategy are used by the students?}

The result of Strategy Inventory of Language Learning (SILL) survey (see Table 1) revealed that the overall students' use of Language Learning Strategy (LLS) was in medium level (3.07). In the six categories of LLS, the participants reported using metacognitive strategies the most and Affective strategy the least. There are three strategies poorly used by the students, the memory, compensation, and affective strategies which lie 2.60 and 2.94 . Meanwhile, the cognitive, metacognitive, and social strategies are in medium use. It can be seen that the students' use of direct strategies is relatively lower than indirect strategies.

Table 2. Student's Use of Language Learning Strategies

\begin{tabular}{ccccc}
\hline & N & Mean & Category & $\begin{array}{c}\text { Std. } \\
\text { Deviation }\end{array}$ \\
\hline LLS as a whole & 30 & 3.07 & Medium Use & \\
\hline Memory & 30 & 2.94 & poor use & .52 \\
\hline Cognitive & 30 & 3.21 & Medium use & .46 \\
\hline Compensation & 30 & 2.94 & poor use & .60 \\
\hline Metacognitive & 30 & 3.57 & Medium use & .69 \\
\hline Affective & 30 & 2.60 & Poor use & .43 \\
\hline Social & 30 & 3.17 & Medium use & .72 \\
\hline
\end{tabular}

The results show despite the fact that the students utilize every one of the six sorts of language learning strategies, they are only poorly or moderately used. This outcome is not quite the same as that found in past research done by Politzer (1983) that stated Asian learners favored memory strategies, for example, retention. Noguchi in 1991 studied Japanese secondary school students' language learning strategy use, and discovered that social strategies were utilized least frequently. Be that as it may, Wharton (2000) analyzed the language learning strategies utilization of college understudies in Singapore, and showed a high mean and ranking of social strategy utilization. This outcome is not in line to that found in this study. In this manner, it could be expected that in the previous decades, students' utilization of language learning strategies has changed. These changes might be a result of 
the advancement of the Internet. This improvement may promote the collaboration and fellowship among western and eastern societies, which may likewise prompt a wide range of social changes, for example, the manner in which a language is learned. The development of the Internet and its influence on culture and education warrants further research.

\subsection{Is there any difference in the learning style and language learning strategies of male and female students?}

An independent sample t-test was conducted to find out whether there is any difference between male and female students learning style and strategies. The statistical results revealed that there is no significant difference in their learning styles (Table 2). This is not in line with the findings of a previous study by Oxford (1994), that suggested a female learning style may be relatively but characteristically 'global' (rather than analytical), 'field dependent' (rather than field-independent), reflective (rather than impulsive) and auditory (rather than visual), while male learning style is the opposite.

Meanwhile, the statistical result for language learning strategies (Table 3) shows a significant difference in students' compensation strategy $(\mathrm{p}<0.05)$, where male students' average use of compensation strategies is higher than that of female students $(3.16>2.72)$. this is also not in line with the finding of Goh and Foong's study, stating that female students tend to use compensation strategies (e.g., guessing unknown words) more than their male counterparts.

Table 3. Perceptual Learning Styles of Male and Female Students

\begin{tabular}{|c|c|c|c|c|c|c|}
\hline & Gender & $\mathbf{N}$ & Mean & $\overline{\text { Df }}$ & $\mathbf{t}$ & $\mathbf{P}$ \\
\hline \multirow[t]{2}{*}{ Visual } & Female & 15 & 3.76 & \multirow{2}{*}{28} & \multirow{2}{*}{1.359} & \multirow{2}{*}{.185} \\
\hline & Male & 15 & 3.55 & & & \\
\hline \multirow[t]{2}{*}{ Auditory } & Female & 15 & 3.80 & \multirow{2}{*}{28} & \multirow{2}{*}{-.634} & \multirow{2}{*}{.531} \\
\hline & Male & 15 & 3.89 & & & \\
\hline \multirow[t]{2}{*}{ Kinesthetic } & Female & 15 & 3.68 & \multirow{2}{*}{28} & \multirow{2}{*}{-.942} & \multirow{2}{*}{.354} \\
\hline & Male & 15 & 3.89 & & & \\
\hline \multirow[t]{2}{*}{ Tactile } & Female & 15 & 3.71 & \multirow{2}{*}{28} & \multirow{2}{*}{-.100} & \multirow{2}{*}{.921} \\
\hline & Male & 15 & 3.73 & & & \\
\hline \multirow[t]{2}{*}{ Group } & Female & 15 & 3.80 & \multirow{2}{*}{28} & \multirow{2}{*}{-.225} & \multirow{2}{*}{.823} \\
\hline & Male & 15 & 3.87 & & & \\
\hline \multirow[t]{2}{*}{ Individual } & Female & 15 & 3.53 & \multirow{2}{*}{28} & \multirow{2}{*}{1.433} & \multirow{2}{*}{.163} \\
\hline & Male & 15 & 3.06 & & & \\
\hline
\end{tabular}

Table 4. Language Learning Strategies of Male and Female Students

\begin{tabular}{lllllll}
\hline & Gender & $\mathbf{N}$ & Mean & Df & t & P \\
\hline \multirow{2}{*}{ Memory } & Female & 15 & 2.90 & \multirow{2}{*}{28} & -.348 & .730 \\
\cline { 2 - 7 } Cognitive & Male & 15 & 2.97 & & & \\
& Female & 15 & 3.12 & 28 & -1.074 & .292 \\
\cline { 2 - 7 } & Male & 15 & 3.30 & & & \\
\hline
\end{tabular}




\begin{tabular}{|c|c|c|c|c|c|c|}
\hline $\begin{array}{l}\text { Compensat } \\
\text { ion }\end{array}$ & Male & 15 & 3.16 & & & \\
\hline \multirow{2}{*}{$\begin{array}{l}\text { Metacognit } \\
\text { ive }\end{array}$} & Female & 15 & 3.56 & \multirow{2}{*}{28} & \multirow{2}{*}{-.028} & \multirow{2}{*}{.978} \\
\hline & Male & 15 & 3.57 & & & \\
\hline \multirow{2}{*}{ Affective } & Female & 15 & 2.57 & \multirow{2}{*}{28} & \multirow{2}{*}{-.338} & \multirow{2}{*}{.738} \\
\hline & Male & 15 & 2.63 & & & \\
\hline \multirow{2}{*}{ Social } & Female & 15 & 3.25 & \multirow{2}{*}{28} & \multirow{2}{*}{.566} & \multirow{2}{*}{.576} \\
\hline & Male & 15 & 3.09 & & & \\
\hline
\end{tabular}

\subsection{Is there a relationship between students' learning style and their language learning strategy preferences?}

The Pearson Product Moment Correlation was used to determine whether there was a statistically meaningful relationship between the learning style preferences and the language learning strategy preferences of the students. While the results indicated that none of the styles had a statistically significant relationship with the memory and affective strategies, it was found that: the visual learning styles had a significant relationship with cognitive and metacognitive strategies; auditory styles had a significant relationship with cognitive and compensation strategy. Meanwhile, social strategy was correlated with kinesthetic, tactile, and group learning styles. Finally, individual style shows no relationship with any strategy.

Table 5. Summary of Significant Relationship between PLS and LLS

\begin{tabular}{lllll}
\hline \multirow{2}{*}{ Styles } & Strategies & $\begin{array}{l}\text { Pearson } \\
\text { Correlation }(\mathbf{r})\end{array}$ & $\mathbf{p}$ & $\mathbf{r}^{\mathbf{2}}(\boldsymbol{\%})$ \\
\hline \multirow{2}{*}{ Visual } & Cognitive & $.55^{* *}$ & .001 & 35 \\
\cline { 2 - 5 } & Metacognitive & $.409^{*}$ & .026 & 17 \\
\hline \multirow{2}{*}{ Auditory } & Cognitive & $.449^{*}$ & .013 & 20 \\
\cline { 2 - 5 } Kinesthetic & Compensation & $.423^{*}$ & .020 & 18 \\
\hline Tactile & Social & $.494^{* *}$ & .006 & 24 \\
\hline Group & Social & $.470^{* *}$ & .009 & 22 \\
\hline
\end{tabular}

*significant at 0.05

**significant at 0.01

From these results, it can be stated that certain learning style will relatively determine students' choice of strategies. With some stable learning styles, a student will determine what kind of stimuli they can respond well in classroom. This is in line with the statement made by Brown (1994) that learning strategies don't work independent from anyone else, but instead are specifically connected to the student's intrinsic learning styles and other identity related variables. Hence, different as they seem to be, these two terms still bear a close relationship to one another. Both contain psychological and emotional components and are indicators of language proficiency. It is suggested that learning style incorporates students' general tendency to utilize certain learning methodologies while maintaining a strategic distance from others (Oxford 1990b).

Oxford (2001) states if there is harmony between (a) a student's learning style and strategy preferences and (b) the instructional methodology and materials, then the student is likely to perform well, feel confident, and experience low anxiety. In contrary, if clashes occur between (a) and (b), the student often performs poorly, lacks of confidence, and experiences significant anxiety. 


\section{Conclusion}

Students' awareness of their own learning style will help them to employ the most suitable strategies in language learning. Therefore, teachers should help students discover and get familiar with their own learning styles and encourage students to experiment with extending their preferred styles. Instructors may use learning style instruments to help students identify their own learning styles. A continuous evaluation will benefit to take notes of students' strength and weaknesses in language learning process.

It is also recommended that teachers should incorporate learning styles into learning strategy training. Learning strategy training based on learning styles would prepare instructors for which kinds of strategies should be taught and how to deal with learners of different learning styles. Since it is possible for students to tap strategies of other styles, explicit training of certain strategies would enable learners to maximize their learning efficiency.

Future research should continue to investigate whether learning style variables interact with other cognitive, affective and personality variables to predict foreign language learning results. By considering the interactive effects of learning styles with other variables, a more insightful analysis in foreign language learning might be obtained. A multiple regression of learning style variables towards any specific strategy will also be helpful to see more precise effects. Moreover, since this study is quantitative, further and deeper analysis of qualitative will give better insights on what the students actually prefer and do in their learning. Besides, a bigger sample will ensure the representative of the study.

\section{References}

Arnot, M., David, M. \& Weiner, G. (1996). Educational reforms and gender equality in schools. Equal Opportunities Commission Research Discussion Series, 17. Manchester: EOC.

Bailey, P., Onwuegbuzie, A. J., \& Daley, C. E. (2000). Using learning style to predict foreign language achievement at the college level. System, 28(1), 115-133.

Behabadi, F. (2013). Learning styles and characteristics of good language learners in the iranian context ( a study on ielts participants ). International Journal on New Trends in Education and Their Implications, 4(2), 41-49.

Boyle, J. P. (1987). Sex differences in listening vocabulary. Language Learning 37(1), $273-$ 84

Brown, H. D. (2007). Principles of language learning and teaching (fourth). Pearson Education.

Brown, H. D. (1994) Principles of language learning and teaching (third edition). New Jersey: Prentice Hall Regents.

Burstall, C. (1975). Factors affecting foreign language learning: a consideration of some recent research findings. Language Teaching and Linguistic, 8, 5

Carson, J.G., \& A. Longhini. (2002). Focusing on learning styles and strategies: a diary study in an immersion setting, Language Learning 52(2), 401-38. 
Clark, A. (1998). Gender on the agenda: factors motivating boys and girls in MFLs. London: CiLT

Ehrman, M.E., and R.L. Oxford. (1990). adult language learning styles and strategies in an intensive training setting, Modern Language Journal 74(3), 311-27.

Ehrman, M., \& Leaver, B. (2003). Cognitive styles in the service of language learning. System, 31, 393-415.

Grenfell, M., \& Harris, V. (1999). Modern languages and learning strategies in theory and practice. London: Routledge.

Keefe, J. W. (1979). Learning style: An overview. In J. W. Keefe (Ed.) Student learning styles: Diagnosing and prescribing program. Reston, VA: National Association of Secondary School Principals.

Littlemore, J. (2001). An empirical study of the relationship between cognitive style and the use of communication strategy, Applied Linguistics 22(2), 241-65.

Noguchi, T. (1991). Review of language learning strategy: research and its implications. Unpublished bachelor's thesis, Tottori University, Tottori, Japan.

Nyikos, M. (1990). Sex-related differences in adult language learning: socialisation and memory factors. Tlie Modem Language Journal, 74(3), 273-8

Oxford, R. L. (1990). Language learning strategies: What every teacher should know. Boston: Heinle and Heinle.

Oxford, R. (1994). La difference continue..... gender differences in second/foreign language learning styles and strategies. In J. Sunderland (2000).

Oxford, R. L., Park-Oh, Y., Ito, S., \& Sumrall, M. (1993a). Factors affecting achievement in a satellite delivered Japanese language program. American Journal of Distance Education, 7, 10-25.

Oxford, R. L., Park-Oh, Y., Ito, S., \& Sumrall, M. (1993b). Learning a language by satellite: What influences achievement? System, 21(1), 31-48.

Oxford, R. (1995). Style Analysis Survey. In Learning styles in the ESL/EFL classroom. https://doi.org/10.1016/j.meegid.2011.03.017

Park, G. (1994). Language learning strategies: Why do adults need them? Manuscript, University of Texas at Austin.

Phillips, V. (1991). A look at learner strategy use and ESL proficiency. The CATESOL Journal, 4, 57-67.

Politzer, R. (1983). An exploratory study of self-reported language learning behaviors and their relation to achievement. Studies in Second Language Acquisition, 6, 54-67.

Reid, J. M. (1987). The learning style preferences of ESL students. TESOL Quarterly, 21 (1), 87-111. 
Rossi-Le, L. (1995). Learning styles and strategies in adult immigrant ESL students. In J. M. Reid (Ed.) Learning styles in the ESL/EFL classroom. (pp. 118-125). New York: Heinle and Heinle Publishers.

Rubin, J. (1975). What the "good language learner" can teach us. TESOL Quarterly, 9 (1), 41-51.

Rubin, J. (1987) Learner strategies: Theoretical assumptions, research history and typology. In A. Wenden and J. Rubin (Eds.), Learner strategies and language learning. (pp. 1529). Englewood Cliffs, New Jersey: Prentice Hall.

Sunderland, J. (2000). Issues of language and gender in second and foreign language education. Language Teaching, 33(04), 203-223.

Tarone, E. (1983). Some thoughts on the notion of 'communicative strategy'. In C. Faerch and G. Kasper (Eds.), Strategies in interlanguage communication. (pp.61-74). London: Longman.

Tabanlioglu, S. (2003). The relationship between learning styles and language learning strategies of pre-intermediate EAP students. Middle East Technical University.

Tran.T.V. (1988). Sex differences in English language acculturation and learning strategies among Vietnamese adults aged 40 and over in the United States. Sex Roles 19(11-12), 747-58.

Wharton, G. (2000). Language learning strategy use of bilingual foreign language learners in Singapore. Language Learning, 50(2), 203-243.

Young, D. J. \& Oxford, R. (1997). A gender-related analysis of strategies used to process written input in the native language and a foreign language. Applied Language Learning 8(1): 43-73. 
